future French satellites Starlette (October 1974), Castor and Pollux (January 1975), D2B (mid-1975), D2B-Gamma (mid-1976) and Dialogue (end of 1977).

Thus the career of Diamant BP4 is practically finished and if a new 'dead period' is to be avoided before the arrival of the launcher Ariane, scheduled for 1980, a replacement must be found immediately.

Several projects are envisaged by CNES, for example a " $Z$ launcher" which would use the two upper stages of Ariane and which could place 575 $\mathrm{kg}$ into low terrestrial orbit $(400 \mathrm{~km})$; the capability of Diamant BP4 is only $170 \mathrm{~kg}$. But in fact the choice of the future national light launcher depends in part on an eventual programme of French military satellites and until now it has been uncertain whether this would make an entrance before 1980 .

\section{The electronic newspaper in view?}

Ian Ridpath

WITH newsprint scarcities the world over. this could be an opportune time to turn into reality the science-fiction dream of an electronic newspaper that flashes information into each home at the touch of a button. And, as a result of a test programme currently under way, that is exactly what could be happening in the United Kingdom within two years.

These exciting plans stem from the realisation that almost every home has a data terminal for receiving visual transmissions-a television set. The broadcasting companies have decided to use this exciting facility to provide an extra service.

By coding the electronic newspaper transmissions on normal television broadcasts, and incorporating a decoder in domestic television receivers, the system can be run without using any extra band space on the already crowded airwaves. According to equipment manufacturers, the extra circuits needed in a new receiver would cost a thoroughly reasonable $£ 20$, although adding a converter to an existing set might cost between $£ 50$ and $£ 100$.

The trick in sending out the data is to use two television scan lines that are normally redundant. These are lines 17 and 18, which remain out of sight at the top of the picture. Each of these lines now contains pulsed information for one 'row' of the electronic newspaper's 'page'. A page is a screenful of data; there are 24 rows on each page and each row has 40 characters. Prototype receivers to pick up this year's forthcoming test transmissions are now being produced by industry.

A newspaper of around 60 pages will be produced at first, although up to 99 pages are possible. The complete set of pages will take less than 30 seconds to build up inside the receiver's store and continual changes will be added, second by second, as the news comes in. An editorial team at the transmitting centre will feed news into a computer, which will encode it for transmission.

This service would be particularly valuable at times such as elections, but for normal use the electronic newspaper is likely to carry sports results, stock market prices, weather reports, and news bulletins. Simple line illustrations will be possible on the system, and the independent channels may well include advertising.

It is difficult to foresee how sales of printed newspapers will be affected by electronic data transmission to the home. Existing radio and television coverage has not destroyed the newspaper market and the summarised information of the electronic newspaper may even increase demand for longer printed reports. But the potential of the system may have more subtle long term effects and there is clearly considerable room for lobbying by interested parties.

At home, the viewer with a suitable receiver will be able to watch television programmes normally until he decides on a change. His set will have a pushbutton console on which he can punch up the page number of the electronic newspaper he wants. Page 1 of the paper will probably be given over to an index of the full contents. The pages of the paper, which have been stored in the receiver, will then be displayed with a header line showing the time to the nearest second, thus increasing the effect of 'instant information'.

Both the BBC and the IBA (Independent Broadcasting Authority) independently developed their own electronic newspaper transimssion systems, which they have been experimenting with since last year. But they have just agreed on an improved common system, engineering details of which are about to be published.

This standard system, which the prototype sets are designed to receive, enables viewers to pick up transmissions on all channels. Test transmissions to nrove the new system's potential are to begin in the autumn, although it is not clear whether members of the public ivill be able to join in the fun of watch. ing the editorial teams iron out their snags.

What is certain is that, after the trial neriod, a decision will be needed by the broadcasting companies, the receiver manufacturers and the Ministry of Posts and Telecommunications to begin full scale public services. It will be a historic decision, for this will be the world's first commercially available system of its kind.

\section{Drug research in the UK}

\section{Peter Newmark}

A Serious failing of the drug companies was recently emphasised by $\mathrm{Dr}$ J. W. Black in his inaugural lecture as professor of pharmacology at University College, London. Returning to academic life after 15 distinguished years with ICI and Smith, Kline and French, he pointed out that industry was primarily interested in research and development of those drugs that might cure the most common diseases. This makes economic sense to the companies but means that those who suffer from rarer complaints are being cheated of their chance of a cure. The victims of, for example, multiple sclerosis and muscular dystrophy are included in this deprived category.

Professor Black offers a two-pronged approach to the alleviation of this imbalance. First, he is instigating a novel degree course aimed at overcoming the deficiences and hence the paucity of academic, pharmacological research. Second, he suggests a National Drug Research Centre to concentrate on those areas neglected by industry. Where the vast funds for this would come from is anybody's guess. It is a sobering thought that of many thousand folic acid antagonists synthesised and investigated to date, only one, methotrexate, offers much to the treatment of cancer. And for those with the rarer disease it is only an inapt comfort that can be sought in the vast array of money-making antidepressants and tranquillisers that pour from the laboratories of the drug companies.

Latest figures compiled by the Office of Health conomics in London show that expenditure on medical research in the United Kingdom topped the $£ 100$ million mark for the first time in the financial year 1972-73. This represented an increase of about one-fifth over the previous year, though must be considerably less in real spending terms. Of the total expenditure, the government contributed $61 \%$, charities and trusts a notable $13 \%$ and the pharmaceutical industry a dwindling $26 \%$.

These statistics give no indication of which areas of medical research benefited most from the funds, let alone what returns were received by the investors, be they the public or shareholders. One thing that is certain is that most pharmaceutical research was done by the relevant industry. This is probably as it should be. To what extent it is in the public interest is less certain and the present government is not averse to nationalising parts of the industry if it feels that this is the best action for the nation. 